\title{
Nosocomial Infection Control in Latin America: We Have to Start Now
}

Latin America is comprised of a group of developing countries with high demographic growth rates, multiple severe health problems, and an increasingly difficult economic situation. Social differences are notorious in these countries and the distribution of health services is related to the economic capabilities of each town or city. Thus only larger, more important cities have modern hospitals with first-class medical assistance while the rest of the country hospitals have very poor facilities.

Even though the available information on nosocomial infection in these countries is scarce, we can infer that infections constitute a major health problem with a frequency that possibly exceeds the $5 \%$ to $10 \%$ reported in the US.' The influence of these infections in mortality, and costs must be proportionately higher as well.

Deficient sanitary systems, inadequate hospital-bed distribution with practically no separation between patients, and the lack of knowledge of nosocomial infection in medical and non-medical personnel are some of the factors that cause higher rates of infection (as have been seen in Mexico and reported in Jamaica). ${ }^{2}$ The medical cost of infection is also probably higher than in developed countries due to longer hospitalization.

Based on these assumptions we can suggest that the magnitude of the problem of nosocomial infection in Latin America is worse than in industrialized countries; however, it has not been fully recognized due to the fact that the few existing reports show low nosocomial infection rates. ${ }^{3-5}$

The reported results were obtained through deficient surveillance systems that do not allow a realistic view of the problem. An example of the situation is the recent experience of a physician with basic training in hospital epidemiology. She started working in a 500-bed hospital in Mexico City where, for several years, the reported rates of nosocomial infection had been lower than $2 \%$. After four weeks of test observations the recorded rate was $6 \%$, even though the surveillance was made with only one nonspecialty trained nurse (M.E. Baridó, personal communication).

The population in Latin America in 1980 was 368 million, and it has been estimated that it will be 608 million by the year 2000, representing a $65 \%$ increase. In 1978 the Pan-American Health Organization (PAHO) reported the existence of 13,410 hospitals in the area with 926,848 beds, most of them with high rates of occupancy. ${ }^{\circ}$ In order to maintain the present bed/inhabitant ratio, $1,529,000$ beds would be needed by the year 2000 . This obviously is difficult to achieve, so the increase in the number of beds must be substituted with improved hospital efficiency. Therefore, we are not only facing a problem today but one that will be increasing in upcoming years, a fact that makes the prompt initiation of control of nosocomial infection mandatory.

At the moment several countries (eg, Costa Rica, Panama, Argentina, Cuba, Colombia, Ecuador and Jamaica) have started to show interest in the problem. Chile has initiated a program in collaboration with $\mathrm{PAHO}$ and more recently Brazil has begun to formulate plans for national infection control. In Mexico several isolated programs exist, but in a few months an ambitious national control program will begin. This increasing interest is a consequence of the potential cost reduction benefits that can be obtained through an Infection Control Program, as was demonstrated by Robert Haley with the SENIC Project.

Problems in Latin American hospitals are different from those in North American hospitals; therefore, their approach must be different, as has been suggested by PAHO. ${ }^{7}$ New solutions must be created according to the existing economic possibilities. It must be kept in mind that Latin American hospitals are impoverished; most of them have difficulty obtaining disposable syringes, closed urinary drainage systems or even sterile gloves. 
Ideally, Latin American countries should organize nationwide programs, starting with the identification of the major problems and their characteristics so that adequate control programs can be designed to solve the outstanding problems. In the beginning these programs must have limited and feasible objectives that may be gradually amplified to obtain higher goals. A relevant aspect must be the economic benefit to achieve, since this will be one of the main reasons for the initiation and support of the control programs.

At present, the subject of nosocomial infections in Latin America is full of questions. What are the real dimensions, the economic impacts, and the best approaches to the problem? Fortunately the European and North American experiences will be of great value, if adequately applied, to find the right answers.

Hospitals in Latin America must start working on nosocomial infections now. The challenge is a great one because of the existing economic problems. It would be highly desirable that a continental program be organized by PAHO. Now is the time.

\section{REFERENCES}

1. Wenzel RP: Surveillance and reporting of hospital acquired infections, in Wenzel RP (ed): Handbook of Hospital Acquired Infections. Boca Raton, FL, CRC Press, 1981.

2. Probhakar P, Raje D, Castle D, et al: Nosocomial surgical infections: Incidence and cost in a developing country. Am Infect Control 1983; 11:51-56.

3. Peredo MA, Manjarrez MA, Rivas-Lopez M, et al: Infecciones adquiridas por pacientes hospitalizados. Etiologia y formas clinicas. Rev̀ Med I.M.S.S. (México) 1981; 19:605-609.

4. Altamirano-Lagarda S, Cárdenas-Romero C: Infecciones adquiridas durante 1979 en el hospital de Especialidades del Centro Médico de Occidente. Rev Med I.M.S.S. (Ḿexico) 1981; 19:599-603.

5. Vargas de la Rosa R, Peniche A, Martinez MC: Tendencias y otras caracteristicas de las infecciones intrahospitalarias en el hospital de Pediatria del CMN, 1977-1980. Rev Med I.M.S.S. (México) 1982; 20:543-555.

6. Las condiciones de salud en las Américas 1977-1980. Pubq. Cientifica No. 427, Organización Panamericana de la Salud. 1982.

7. Western KA, St. John RK, Shearer LA: Hospital infection control: An international perspective. Infect Control 1982; 3:453-455.

Samuel Ponce de León Rosales, MD Department of Infectious Diseases Hospital Epidemiologist Instituto Nacional de la Nutrición "Salvador Zubirán" México 